\title{
Dorsal-ventral patterning of the spinal cord requires Gli3 transcriptional repressor activity
}

\author{
Madelen Persson, ${ }^{1,5}$ Despina Stamataki, ${ }^{2,5}$ Pascal te Welscher, ${ }^{3}$ Elisabet Andersson, ${ }^{1}$ Jens Böse, ${ }^{4}$ \\ Ulrich Rüther, ${ }^{4}$ Johan Ericson, ${ }^{1,6}$ and James Briscoe ${ }^{2,6}$ \\ ${ }^{1}$ Department of Cell and Molecular Biology, Medical Nobel Institute, Karolinska Institute, S-171 77 Stockholm, Sweden; \\ ${ }^{2}$ Developmental Neurobiology, National Institute for Medical Research, London, NW7 1AA, UK; ${ }^{3}$ Department of \\ Developmental Biology, Faculty of Biology, Utrecht University, $3584 \mathrm{CH}$ Utrecht, The Netherlands; ${ }^{4}$ Institut für \\ Entwicklungs- und Molekularbiologie der Tiere (EMT), Heinrich-Heine-Universität, 40225 Düsseldorf, Germany
}

Sonic hedgehog (Shh) plays a critical role in organizing cell pattern in the developing spinal cord. Gli proteins are thought to mediate Shh signaling, but their role in directing neural tube patterning remains unclear. Here we identify a role for Gli3 transcriptional repressor activity in patterning the intermediate region of the spinal cord that complements the requirement for Gli2 in ventral regions. Moreover, blocking all Gli responses results in a complete dorsalization of ventral spinal cord, indicating that in addition to the specific roles of Gli2 and Gli3 in the neural tube, there is functional redundancy between Gli proteins. Finally, analysis of Shh/Gli3 compound mutant mice substantiates the idea that ventral patterning may involve a mechanism independent, or parallel, to graded Shh signaling. However, even in the absence of graded Shh signaling, Gli3 is required for the dorsal-ventral patterning of the intermediate neural tube. Together these data raise the possibility that Gli proteins act as common mediators integrating Shh signals, and other sources of positional information, to control patterning throughout the ventral neural tube.

[Keywords: Shh, Gli, neural tube, dorsal-ventral patterning]

Received July 25, 2002; revised version accepted September 9, 2002.

The Hedgehog (Hh) family of secreted signaling molecules have central roles in embryonic development. In ventral regions of the central nervous system, Sonic hedgehog (Shh) controls the specification of progenitor cell fate and neuronal subtype identity (Jessell 2000; Briscoe and Ericson 2001; Ingham and McMahon 2001), and accumulating evidence suggests that Shh acts as a long-range graded signal to control neural pattern in a concentration-dependent manner (Ericson et al. 1997; Hynes et al. 2000; Briscoe et al. 2001; Gritli-Linde et al. 2001; Lewis et al. 2001).

In the spinal cord, distinct neuronal subtypes emerge in a precise spatial order from progenitor cells arrayed along the dorsal-ventral axis of the neural tube, and this pattern of neurogenesis is controlled by secreted signals that partition neural progenitor cells into spatially discrete domains (Briscoe et al. 2000). BMP and Wnt signals emanating from the roof plate and overlaying ectoderm initiate patterning from the dorsal neural tube (Lee and Jessell 1999), whereas within the ventral spinal cord, the

\footnotetext{
${ }^{5}$ These authors contributed equally to this work.

${ }^{6}$ Corresponding authors.

E-MAIL johan.ericson@cmb.ki.se; FAX 46-8-30-83-74.

E-MAIL james.briscoe@nimr.mrc.ac.uk; FAX 44-20-8913-8536.

Article and publication are at http://www.genesdev.org/cgi/doi/10.1101/ $\operatorname{gad} .243402$.
}

secretion of Shh from the notochord and floor plate has a key role in establishing ventral neuronal fates (Chiang et al. 1996; Ericson et al. 1996; Briscoe et al. 2001). Shh signaling acts by regulating the spatial pattern of expression, in ventral progenitor cells, of transcription factors that include homeodomain proteins of the Nkx, Pax, Dbx, and Irx families and the bHLH protein Olig2 (Ericson et al. 1997; Pierani et al. 1999; Briscoe et al. 2000; Muhr et al. 2001; Novitch et al. 2001; Vallstedt et al. 2001). These transcription factors are subdivided into two groups, termed class I and II proteins, on the basis of their mode of regulation by Shh signaling (Briscoe et al. 2000). The class I proteins are constitutively expressed by neural progenitor cells, and their expression is repressed by Shh signaling, whereas neural expression of the class II proteins requires exposure to Shh (Ericson et al. 1997; Qiu et al. 1998; Briscoe et al. 1999, 2000; Pabst et al. 2000; Vallstedt et al. 2001). Although manipulation of Shh signaling changes the pattern of class I and class II gene expression in predictable fashion (e.g., Briscoe et al. 2001), it remains unclear how graded Shh signaling controls the early steps of differential gene expression in the ventral neural tube.

The molecular mechanisms of Hh signaling are best understood in Drosophila, where the zinc finger containing transcription factor Cubitus interruptus $(\mathrm{Ci})$ is criti- 
cal to Hh-mediated control of gene expression (Ingham 1998; Ingham and McMahon 2001; Methot and Basler 2001). In the absence of $\mathrm{Hh}$ signaling, $\mathrm{Ci}$ is proteolytically processed into a truncated repressor form that inhibits Hh target genes (Aza-Blanc et al. 1997; Robbins et al. 1997). The processing of $\mathrm{Ci}$ is inhibited by Hh signaling, which converts $\mathrm{Ci}$ into a transcriptional activator (Ohlmeyer and Kalderon 1998; Methot and Basler 1999; Jia et al. 2002; Price and Kalderon 2002). In vertebrates, three homologs of $\mathrm{Ci}$, that is, Gli1, Gli2, and Gli3 (Hui et al. 1994; Marigo et al. 1996; Ruppert et al. 1988) have been identified and are expressed in the neural tube (Lee et al. 1997; Sasaki et al. 1997; Ruiz i Altaba 1998; Ingham and McMahon 2001). Biochemical studies indicate that Gli2 and Gli3 (although not Gli1) can be proteolytically processed in a manner similar to Ci (Dai et al. 1999; Aza Blanc et al. 2000; Wang et al. 2000); however, the processing of Gli2 was not regulated by $\mathrm{Hh}$, and the relevance of such processing in vivo remains to be determined. Studies in mice indicate that the lack of Gli1 does not affect dorsal-ventral patterning of the spinal cord (Matise et al. 1998; Park et al. 2000), whereas embryos lacking Gli2 have defects in the most ventral regions of the neural tube (Ding et al. 1998; Matise et al. 1998; Park et al. 2000). These defects can be rescued by replacing Gli2 with Gli1, leading to the suggestion that only the activator function of Gli2 is required in the neural tube (Bai and Joyner 2001). Gain-of-function experiments suggest that Shh signaling acts to repress an inhibitory activity of Gli3 (Lee et al. 1997; Ruiz i Altaba 1998; Sasaki et al. 1999; von Mering and Basler 1999; Aza Blanc et al. 2000). Consistent with this, in mice lacking both Shh and Gli3, development of motor neurons (MNs) and ventral interneurons is rescued (Litingtung and Chiang 2000).

These studies leave three critical issues unresolved. First, no defects have been described in the spinal cord of mice lacking Gli3 (Ruiz i Altaba 1998; Park et al. 2000), even though the loss of other negative regulators of Shh signaling such as Ptc1 and Rab23 results in dorsal-ventral patterning defects (Goodrich et al. 1997; Eggenschwiler et al. 2001). Second, although embryos lacking Shh signaling display dramatic patterning defects resulting in the loss of most ventral neuronal subtypes (Chiang et al. 1996; Pierani et al. 1999), the loss of individual Gli genes has relatively minor defects, with MNs and V2 neurons being generated in each of the Gli null mutant embryos (Ding et al. 1998; Matise et al. 1998; Litingtung and Chiang 2000; Park et al. 2000). This could be explained by the presence of Gli repressor activity in $\mathrm{Shh}^{-/}$ mutants that dominate in the absence of Shh-induced Gli activator function, whereas functional redundancy between Gli proteins may explain the generation of MNs and V2 neurons in individual Gli null mutants. Alternatively, transcription factors other than Gli proteins may operate to control the generation of some cell types in the ventral neural tube. Indeed, Krishnan et al. (1997) reported evidence of a phosphatase-activated transcription factor that acts to specify MNs independent of Gli proteins. Third, although the generation of ventral neu- ronal subtypes in Shh/Gli3 double-mutant mice suggests that a Shh-independent patterning mechanism operates in the ventral neural tube (Litingtung and Chiang 2000), it is not clear whether the pattern of class I and class II protein expression is restored in double-mutant embryos. The extensive migration of neurons following their generation leaves open the possibility that in Shh/ Gli3 mutants, the dorsal-ventral pattern of progenitor identity is not restored, and instead neurons are generated stochastically, irrespective of dorsal-ventral position, subsequently migrating to reside in appropriate locations (Wichterle et al. 2002).

Here we describe experiments that address these three issues. First, we identified a specific requirement for Gli3 repressor activity in the neural tube. In mouse embryos lacking Gli3, there is a dorsal expansion of progenitor domains in the intermediate spinal cord, at the expense of more dorsal progenitors. These defects are rescued in embryos carrying a targeted allele of Gli3 that encodes solely a repressor variant equivalent to proteolytically processed Gli3 (Böse et al. 2002). Second, using a dominant repressor version of Gli, we demonstrate that inhibition of Gli transcriptional activation blocks the generation of MNs and V2 neurons in vivo, and results in the dorsalization of the ventral neural tube, indicating that Gli activity is required to direct patterning throughout the ventral spinal cord. Third, we show that the pattern of progenitor domains and neuronal subtype identity is, to a large extent, restored in embryos lacking both Gli3 and Shh, substantiating the idea that ventral patterning can proceed via a mechanism independent of, or parallel to, graded Shh signaling. However, the requirement for Gli3 to correctly pattern the intermediate neural tube remains evident in the Gli3/Shh double-mutant embryos. These findings are consistent with a model in which Gli proteins act as common mediators of spinal cord dorsal-ventral patterning, integrating Shh signals and other sources of positional information, throughout the ventral neural tube.

\section{Results}

We assessed dorsal-ventral patterning in the neural tube of $X t^{I} / X t^{I}$ mice that lack Gli3. We first examined the expression of the floor plate markers Shh and HNF3 $\beta /$ FoxA2, as it has previously been reported that E12.5 Xt/ $X t^{I}$ embryos display low levels of ectopic Shh in $30 \%$ of the cases (Ruiz i Altaba 1998). However in the embryos examined here between E9.5 and E12.5 ( $\mathrm{n}=12)$, expression of Shh and HNF3 $\beta /$ FoxA2 in the spinal cord was indistinguishable from that of wild-type littermates, and we did not detect any evidence of ectopic Shh signaling (Fig. 1A,B; data not shown). This difference may reflect the different embryonic ages examined or may be a consequence of differences in the genetic background of the $X t^{I}$ animals used in this study.

\section{Dorsal-ventral patterning defects in spinal cord progenitors of $\mathrm{Xt}^{\mathrm{J}} / \mathrm{Xt}^{\mathrm{J}}$ embryos}

Because the lack of Gli3 does not affect specification of the floor plate or the expression of Shh in the spinal cord, 


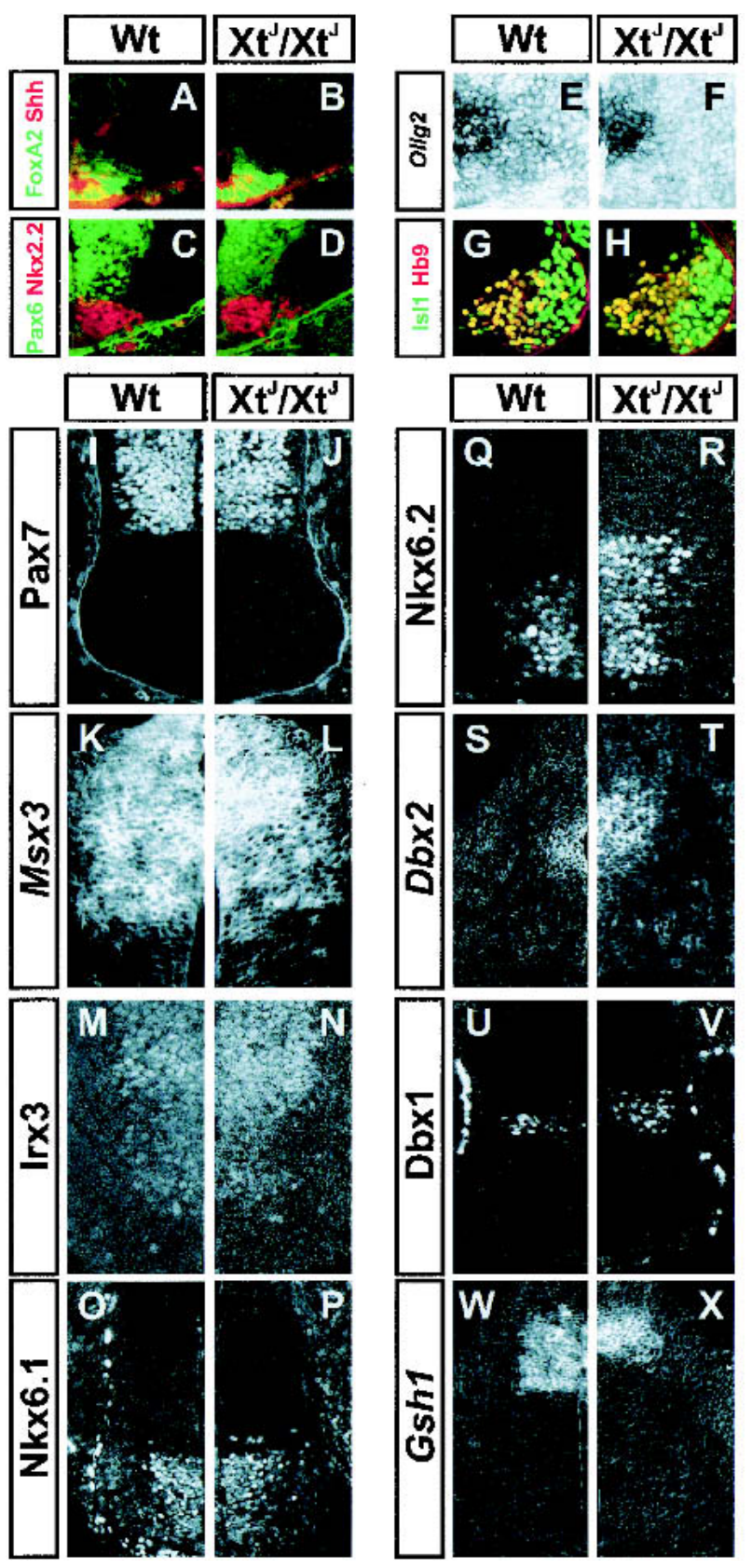

we analyzed dorsal-ventral patterning in Gli3 mutant embryos. For clarity and based on the analysis described below, we have divided the spinal cord into four territories: Region $\mathrm{A}$, encompassing the floor plate and progenitors (p) of V3 neurons, comprises the domains affected in embryos lacking Gli2. Region B comprises the progenitors $\mathrm{pMN}$ and $\mathrm{p} 2$ that generate $\mathrm{MNs}$ and $\mathrm{V} 2$ neurons and is situated dorsal to $\mathrm{p} 3$ and ventral to $\mathrm{Dbx} 2$ expression. Region C comprises the progenitor domains p1, p0, dI6 that express Dbx2. Region D contains the progenitor domains dI5-dI1 dorsal to the region of Dbx2 expression (Fig. 1Y, see Fig. 6, below). First, we focused on Regions A and B. In E10.5 embryos, the expression of the Region A markers Nkx2.2 and Sim1, which are expressed by p3

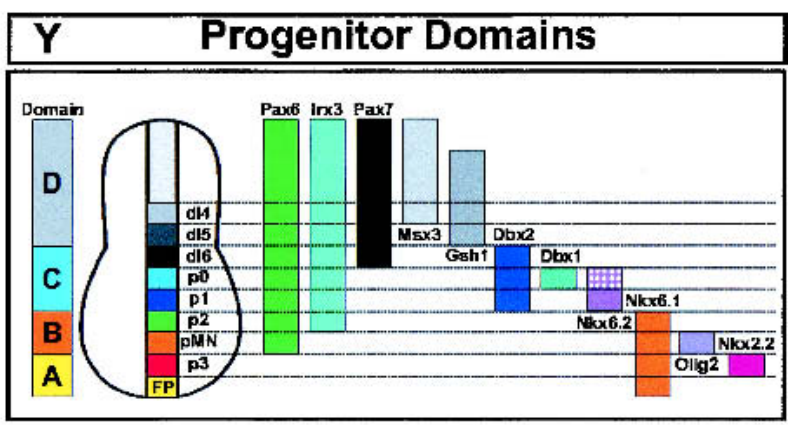

Figure 1. Dorsal-ventral patterning of neural progenitors in spinal cord of E10.5 wild-type (Wt) and Gli3 mutant embryos $\left(X t^{\top}\right)$. $(A, B)$ Expression of Shh (red) and HNF3 $\beta / F o x A 2$ (green) is the same in Wt $(A)$ and $X t^{J} / X t^{J}(B)$ embryos. $(C-F)$ Markers of ventral progenitor domains Nkx2.2 (red, $C, D$ ), Pax6 (green, $C, D$ ), and Olig2 $(E, F)$ are unaffected by loss of Gli3. Analysis of Pax6 (Sey mutants) indicates that Pax6 expression is not required for Gli3 expression (data not shown). $(G, H)$ The generation of HB9- (red) and Isl1- (green) expressing somatic motor neurons is the same in $\mathrm{Wt}(G)$ and $X t^{J} / X t^{J}(H)$ embryos. $(I-N)$ The expression of Pax7 $(I, J)$, $M s \times 3(K, L)$, and Irx3 $(M, N)$ are the same in $\mathrm{Wt}(I, K, M)$ and $X t^{I} / X t^{I}$ $(J, L, N)$ embryos. $(O, P)$ Nkx6.1 expression. There is a marked increase in the number of $\mathrm{Nkx} 6.1^{+}$progenitors positioned dorsal to its normal limit of expression in Region $\mathrm{D}$ of $X t^{J} / X t^{I}$ embryos $(P)$ compared to Wt $(O)$. $(Q-V)$ The dorsal limits of $\mathrm{Nkx} 6.2(Q, R)$, $D b x 2(S, T)$, and Dbx1 $(U, V)$ are expanded dorsally in the absence of Gli3 $(R, T, V)$ compared to Wt $(Q, S, U)$. $(W, X)$ Compared to Wt littermates $(W)$, the ventral limit of Gsh1 expression is closer to the dorsal midline in $X t^{J} / X t^{I}$ embryos. ( $Y$ ) Diagram summarizing spinal cord progenitor expression domains. All embryos are E10.5. Protein detection was by immunohistochemistry, and mRNA detection was by in situ hybridization. Images shown are of forelimb levels; similar data were obtained from sections of neural tube at hindbrain and hindlimb levels (not shown).

progenitors and V3 neurons (Briscoe et al. 1999), were unaffected in $X t^{I} / X t^{I}$ embryos (Fig. 1C,D; data not shown). Moreover, within Region $\mathrm{B}$ the expression of the pMN markers Pax6, Nkx6.1, and Olig2 (Fig. 1C-F,O,P; Novitch et al. 2001) and the expression of the MN markers HB9 and Isl1/2 were normal in $X t^{I} / X t^{I}$ embryos (Fig. $1 \mathrm{G}, \mathrm{H}$; Ericson et al. 1992; Tanabe et al. 1998). The ventral limit of Irx3 expression (Fig. 1M,N) and the ventral limit of V2 neuron generation marked by Chx10 expression (Fig. 2I,J) was also normal in $X t^{I} / X t^{I}$ mice. These data indicate that Gli3 is dispensable for the patterning of Regions $\mathrm{A}$ and $\mathrm{B}$.

We next turned our attention to Region C (see summary Fig. 1Y). The ventral limit of Pax7 and Msx3 ex- 

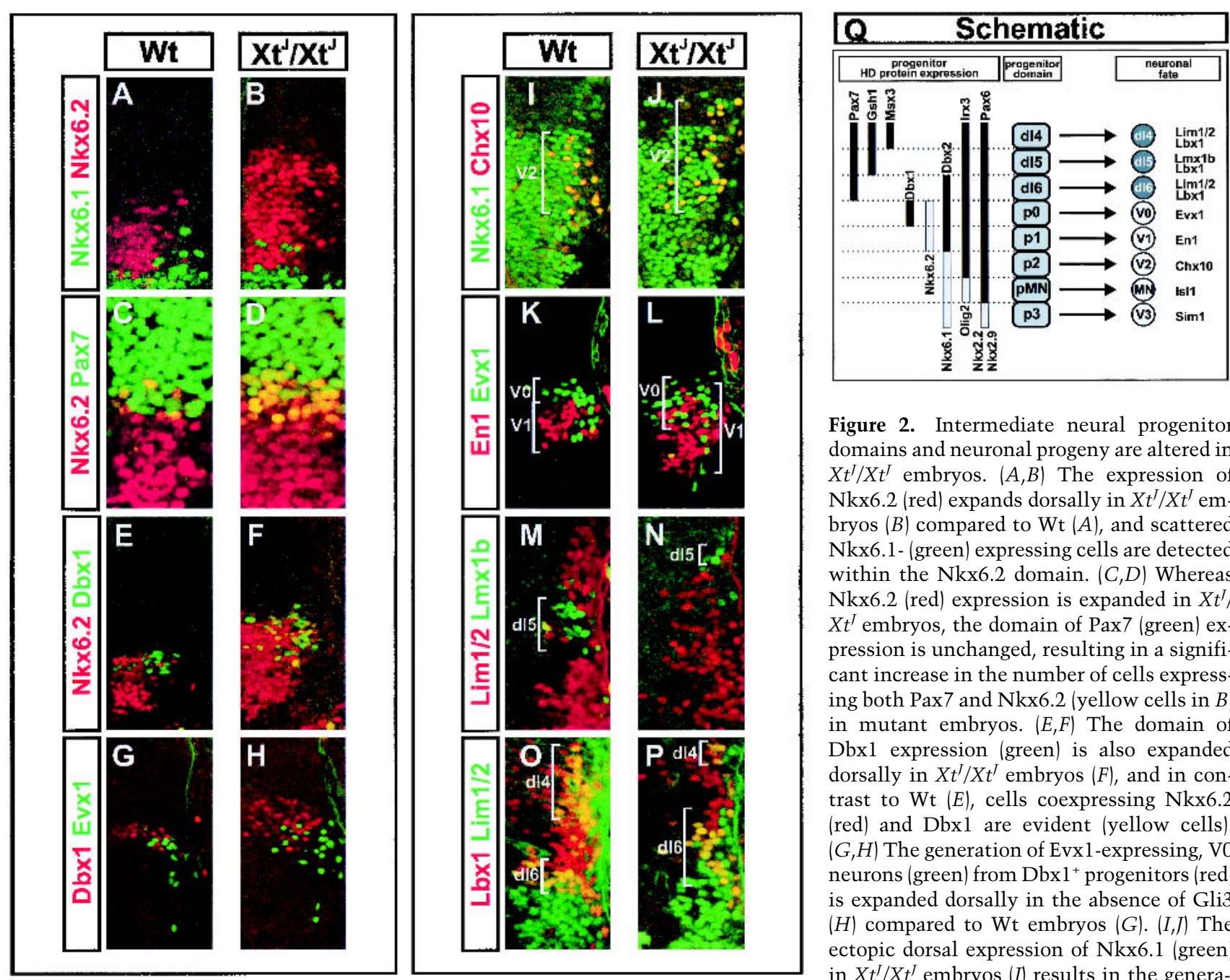

Figure 2. Intermediate neural progenitor domains and neuronal progeny are altered in $X t^{I} / X t^{I}$ embryos. $(A, B)$ The expression of Nkx6.2 (red) expands dorsally in $X t^{J} / X t^{J}$ embryos $(B)$ compared to $\mathrm{Wt}(A)$, and scattered Nkx6.1- (green) expressing cells are detected within the Nkx6.2 domain. $(C, D)$ Whereas Nkx6.2 (red) expression is expanded in $X t^{I}$ / $X t^{I}$ embryos, the domain of Pax7 (green) expression is unchanged, resulting in a significant increase in the number of cells expressing both Pax7 and Nkx6.2 (yellow cells in B) in mutant embryos. $(E, F)$ The domain of Dbxl expression (green) is also expanded dorsally in $X t^{I} / X t^{I}$ embryos $(F)$, and in contrast to $\mathrm{Wt}(E)$, cells coexpressing Nkx6.2 (red) and Dbx1 are evident (yellow cells). $(G, H)$ The generation of Evx1-expressing, V0 neurons (green) from $\mathrm{Dbxl}^{+}$progenitors (red) is expanded dorsally in the absence of Gli3 $(H)$ compared to Wt embryos $(G)$. $(I, J)$ The ectopic dorsal expression of Nkx6.1 (green) in $X t^{J} / X t^{I}$ embryos $(J)$ results in the generation of Chx10- (red) expressing V2 neurons in ectopic dorsal positions. $(K, L)$ En1-expressing V1 neurons (red) and Evx1-expressing V0 neurons (green). In $X t^{J} / X t^{J}$ embryos $(L)$, V1 neuron generation can be detected dorsal to the normal limit, intermingled with V0 neurons. $(M, N)$ The generation of Lmxlb- (green expressing dI5 neurons is significantly reduced in $X t^{I} / X t^{J}$ embryos $(N)$, and the region in which these neurons are usually specified generates Lim $1 / 2$ - (red) expressing neurons. $(O, P)$ The generation of dI6 neurons which express Lbx1 (red) and Lim1/2 (green) is expanded dorsally in the absence of Gli3, whereas the generation of dI4 neurons is reduced $(P)$. (Q) Summary indicating the relationship between progenitor proteins and neuronal subtype identity. Images shown are of forelimb levels with the exception of $I$ and $J$, which are from rhombomere 8 of the hindbrain. Similar data were obtained from sections of neural tube at hindbrain and hindlimb levels (not shown).

pression was unaltered in $X t^{I} / X t^{J}$ embryos (Fig. 1I-L). However, in embryos lacking Gli3 there was a dramatic dorsal expansion in the domains of three homeodomain proteins, Nkx6.2, Dbx2, and Dbx1, expressed in Region C (Fig. 1Q-V). The expression of Nkx6.2, Dbx1, and $D b x 2$ was expanded up to 10 cell diameters in $X t^{I} / X t^{I}$ embryos, resulting in an approximately twofold increase in the size of these domains compared to wild-type litter mates (e.g., Fig. 1, cf. Q and R), and a decrease in the distance between the dorsal limit of expression of each of these genes and the dorsal midline.

Concomitant with this, the expression of Gsh1 was reduced in $X t^{I} / X t^{I}$ mutants. Gsh1 expression marks the ventral limit of Region D (Fig. 1W, X; see summary Fig. $1 \mathrm{Y})$, and in $X t^{I} / X t^{I}$ embryos the ventral limit of expression retracted closer to the roof plate. Dorsal to this, the ventral boundary of Gsh2 expression was similar in wildtype and $X t^{I} / X t^{I}$ mutants (data not shown), indicating that the absence of Gli3 results in the loss of only the ventral parts of Region D. Together these data indicate that in the absence of Gli3, there is a dorsal-ventral switch in progenitor identity in intermediate regions of the spinal cord resulting in the dorsal expansion of Region $\mathrm{C}$ at the expense of Region D.

We examined in more detail the expression of progenitor homeodomain proteins in Region C. In control em- 
bryos, Nkx6.2 is primarily expressed in the p1 domain with scattered $\mathrm{Nkx} 6.2^{+}$cells found in the p0 domain, intermingled with $\mathrm{Dbx}^{+}$cells (Vallstedt et al. 2001). In embryos lacking Gli3, there was a robust dorsal expansion of Nkx6.2 (Fig. 2A-D), resulting in the domain of Nkx6.2 expression extending a number of cell diameters into the Pax7 expression domain (Fig. 2C,D). In control embryos, only a small number of cells coexpress Nkx6.2 and $\operatorname{Pax} 7(10 \pm 4$ cells/section, $n=4)$, whereas in the absence of Gli3 there were significant numbers of Nkx6.2 $2^{+}$ cells coexpressing Pax7 (43 \pm 9 cells/section, $n=4)$. In $X t^{I} / X t^{I}$ embryos there was also an increase in the domain of cells that express Dbxl and the number of cells that coexpressed both Nkx6.2 and Dbx1 (Fig. 2E,F), in contrast to control embryos, where few if any cells coexpressed Dbx1 and Nkx6.2. Thus in the absence of Gli3, each progenitor domain in Region $\mathrm{C}$ expands dorsally, and the resultant progenitor domains express combinations of homeodomain proteins not seen in wild-type embryos.

There was also a marked increase in the number of Nkx6.1 $1^{+}$progenitors positioned dorsal to the ventral limit of Nkx6.2 expression in $X t^{J} / X t^{J}$ embryos (Fig. $2 \mathrm{~A}, \mathrm{~B}, \mathrm{I}, \mathrm{J} ;$ at $\mathrm{r} 8$ levels in wt animals, $7 \pm 2$ Nkx6.1 cells/ section, $n=4$, were positioned dorsal to the ventral limit of Nkx6.2; in $X t^{J} / X t^{I}$ embryos, $36 \pm 15$ cells/section, $\mathrm{n}=4$ ). However, the expression of Nkx6.2 and Nkx6.1 remained mutually exclusive (Fig. 2A,B). These data raise the possibility that although $\mathrm{Nkx6} 6.1$ continues to repress Nkx6.2, the patterning or sorting of the expression domains of Nkx6 genes in Region $\mathrm{C}$ is disrupted in the absence of Gli3. Together the results indicate that Gli3 is required for the correct dorsal-ventral patterning of progenitor domains in the intermediate spinal cord.

\section{Defects in the pattern of neuronal generation in $\mathrm{Xt}^{\mathrm{J}} / \mathrm{Xt}^{\mathrm{J}}$ embryos}

The region of the neural tube affected in Gli3 mutant embryos encompasses the progenitors of at least six neuronal classes: V2, V1, V0, dI6, dI5, and dI4 neurons (Fig. 2G-Q; Briscoe et al. 2000; Pierani et al. 2001; Vallstedt et al. 2001; Gross et al. 2002; Müller et al. 2002). Using molecular markers for each subtype, we examined whether the generation of these neuronal classes is impaired in Gli3 mutants. V2 neurons are defined by the expression of Chx10 and are normally generated dorsal to MNs and ventral to En1-expressing V1 neurons from progenitors that express Nkx6.1 and Irx3 (Briscoe et al. 2000). Consistent with the finding that there was a significant increase in the number of cells expressing Nkx6.1 dorsal to their normal position in $X t^{I} / X t^{I}$ embryos, ectopic V2 neurons were observed in Region C, intermingled with En $1^{+} \mathrm{V} 1$ neurons in mutant embryos but not in wild-type littermates (Fig. 2I,J).

We next examined the generation of Region $C$ neurons V1, V0, and dI6. V1 and V0 neurons express En1 and Evx1, respectively (Pierani et al. 2001), and are generated ventral to the Pax7 boundary (Pierani et al. 2001; Vallstedt et al. 2001); dI6 neurons express Lbx1 and Lim1/2 and are generated dorsal to the Pax 7 boundary (Gross et al. 2002; Müller et al. 2002). In $X t^{I} / X t^{J}$ embryos, there was a marked dorsal expansion in the domain of generation of V1, V0, and dI6 neuronal subtypes (Fig. 2G,H,K,L,O,P). Moreover, En1-expressing V1 neurons were detected intermingled with Evx1 ${ }^{+}$V0 neurons (Fig. 2K,L). In wildtype embryos, V1 and V0 neurons are generated in distinct dorsal-ventral domains (Pierani et al. 2001; Vallstedt et al. 2001), V1 neurons from Dbx2-expressing progenitors, and V0 neurons from $\mathrm{Dbx}^{+}$progenitors. Thus, the alteration of progenitor domain identity observed in the absence of Gli3 is accompanied by a dorsal expansion of the neuronal subtypes generated by these progenitors, and in contrast to wild-type embryos, there is an intermingling of neuronal subtypes.

The dorsal expansion of V1, V0, and dI6 neurons and parallel repression of Gsh1 in $X t^{I} / X t^{I}$ mice raised the possibility that neuronal subtypes characteristic of Region $\mathrm{D}$ might be affected. To test this, the generation of dI4 and dI5 neurons was examined (Fig. 2M-P). dI5 neurons express the homeodomain proteins Lbx1 and Lmx1b but not Lim $1 / 2$, whereas dI 4 neurons express Lbx 1 and Lim $1 / 2$ and are generated dorsal to dI5 neurons (Gross et al. 2002; Müller et al. 2002). In wild-type littermates, Lmx1b-expressing neurons occupy a position within the Gsh1/Pax7-expressing territory (Fig. 2M,Q). In $X t^{J} / X t^{J}$ embryos, the production of dI5 was reduced by $\sim 70 \%$, and it was in this domain that the expansion of dI6 neurons was observed (Fig. 2N-Q). Moreover, the domain of dI4 neurons was also reduced (Fig. 2O,P). Together the data indicate that the changes in the expression patterns of homeodomain proteins in the intermediate neural tube of $X t^{J} / X t^{I}$ embryos are accompanied by corresponding changes in the neuronal subtype generated.

Repressor activity of Gli3 rescues patterning in the neural tube of $\mathrm{Xt}^{\mathrm{J}} / \mathrm{Xt}^{\mathrm{J}}$ embryos

The data identify a requirement for Gli3 in controlling dorsal-ventral patterning and cell fate in the intermediate neural tube. To test whether repressor and/or activator function of Gli3 is required for this function, we took advantage of a targeted mutation in Gli3, Gli3 ${ }^{\Delta 699}$, that results in a premature termination of translation of Gli3 C-terminal of the zinc finger region (Fig. 3A; Böse et al. 2002). As a consequence, these mice encode a truncated Gli3 protein similar to the proposed proteolytically processed Gli3 repressor isoform (Fig. 3A; Böse et al. 2002). This premature termination is in close proximity to the mutations identified in Pallister-Hall syndrome patients, and consistent with this, mice homozygous for the mutation display a range of developmental abnormalities encompassing almost all of the common Pallister-Hall syndrome features, including imperforate anus; gastrointestinal, epiglottis, and larynx defects; abnormal kidney development; and absence of adrenal glands (Böse et al. 2002). In the neural tube, the expression of the Gli3 ${ }^{\Delta 699}$ is essentially the same as transcripts from the wild-type allele (Fig. 3B,C; Böse et al. 2002), allowing us to test 
Figure 3. Patterning defects in $X t^{I} / X t^{J}$ embryos are rescued by a repressor variant of Gli3. (A) Summary of the Gli3 ${ }^{\Delta 699}$ allele and the product of this allele. $(B, C)$ Expression of Gli3 in Gli3 ${ }^{\Delta 699 / \Delta 699}$ and Wt is similar in the neural tube. The level of transcript appeared similar in wild-type and Gli3 ${ }^{\Delta 699 / \Delta 699}$ embryos; however, it is unclear how RNA levels relate to protein levels. Nevertheless expression of Gli3 ${ }^{\Delta 699}$ was sufficient to rescue the patterning defects seen in the neural tube of $X t^{I} / X t^{I} \mathrm{em}$ bryos (see below). $(D-F)$ The expansion of Nkx6.2 expression (red) observed in $X t^{\top} /$ $X t^{J}$ embryos $(E)$ is not seen in Gli3 ${ }^{\Delta 699 / \Delta 699}$ embryos $(F)$, and expression of Nkx6.1 (green) in Gli3 $3^{\Delta 699 / \Delta 699}$ embryos is restricted ventral to the $\mathrm{Nkx} 6.2$ boundary. $(G-I)$ Pax7 (green) and Nkx6.2 (red) are similar in Wt $(G)$ and $G l i 3^{\Delta 699 / \Delta 699}(I)$ embryos, with few if any cells coexpressing both proteins. (J-L) Dbx1 (green) and Nkx6.2 (red) are similar in $\mathrm{Wt}(J)$ and Gli3 $^{\Delta 699 / \Delta 699}(L)$ embryos; few if any cells coexpress both proteins. $(M-O)$ The generation of V1 neurons (red) and V0 neurons (green) is similar in $\mathrm{Wt}(M)$ and Gli3 ${ }^{\Delta 699 / \Delta 699}(O)$ embryos. $(P-R)$ The generation of Lmxlb-expressing dI5 neurons (green), which are significantly depleted in $X t^{J} / X t^{I}$ embryos, are restored in $\mathrm{Gli}^{\Delta 699 / \Delta 699}$ $(R)$ embryos, and these neurons do not express Lim1/2 (red). (S-U) Gsh1 expression is similar in Wt $(S)$ and Gli3 $3^{\Delta 699 / \Delta 699}(U)$ embryos. Moreover, no difference in the expression of progenitor or neuronal markers in Regions A or B was observed. All sections are from E10.5 embryos. Similar results were obtained with Gli3 ${ }^{\Delta 699 / \Delta 699}$ and Gli3 ${ }^{\Delta 699 / X t J}$ embryos. Protein detection was by immunohistochemistry, and mRNA detection was by in situ hybridization.
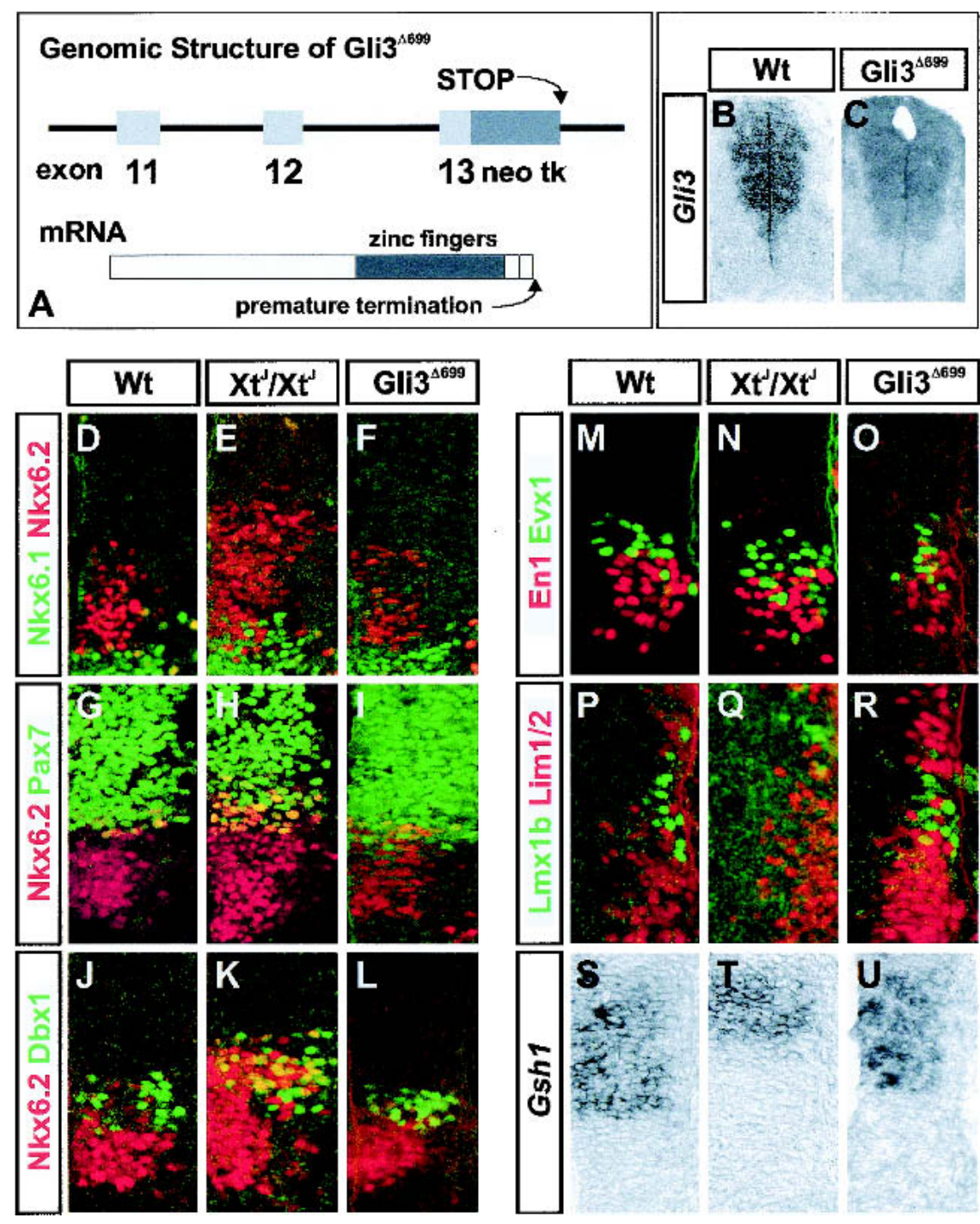

Gli3 $^{\mathrm{as9}}$
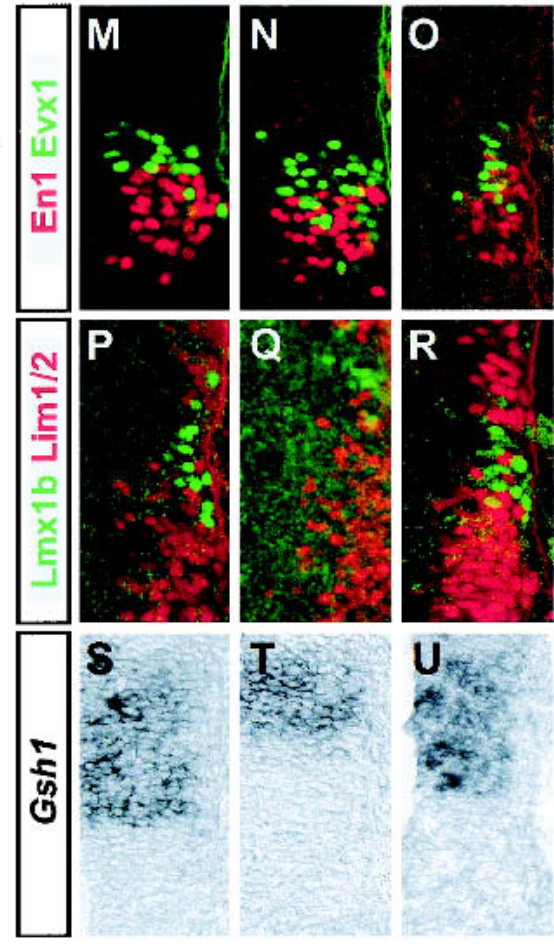

whether Gli3 ${ }^{\Delta 699}$ is sufficient to rescue the defects in patterning observed in Gli3 mutant mice.

We examined the expression of progenitor homeodomain proteins and the generation of neuronal subtypes affected in Gli3 mutants. Region C was normal: the expression of Nkx6.2 and Dbx1 in Gli3 ${ }^{\Delta 69 / \Delta 699}$ embryos was similar to that in wild-type littermates (Fig. 3D-L); no expansion in the expression of either gene was detected, and only rare cells coexpressed Nkx6.2 and Pax7 (Fig. 3G-I) or Nkx6.2 and Dbx1 (Fig. 3J-L). Consistent with this, in Gli3 ${ }^{\Delta 699 / \Delta 699}$ embryos, the expression domain of the Region D marker Gsh1 was restored (Fig. 3S-U), expression of Nkx6.1 was confined to its normal domain (Fig. 3D-F), and no ectopic Nkx6.1 cells were detected within the Nkx6.2 domain (Fig. 3D-F). More over, the generation of V1 and V0 neurons in Gli3 ${ }^{\Delta 699 / \Delta 699}$ embryos was similar to that in wild-type embryos (Fig. 3M-O), and the numbers and position of Lmxlbexpressing dI5 neurons, significantly depleted in Gli3 mutants, were similar to those in wild-type embryos
(Fig. 3P-R). The generation of other neuronal subtypes in the ventral neural tube, including dI4, dI6, MNs, and V2 neurons was equivalent to wild-type in Gli3 ${ }^{\Delta 699 / \Delta 699} \mathrm{em}$ bryos (data not shown). Together these data indicate that Gli3 $3^{\Delta 69 / \Delta 699}$ is sufficient to substitute for wild-type Gli3 in the neural tube, providing evidence of a role for Gli repressor activity in vertebrate embryos.

\section{Dorsal-ventral pattern of progenitors in Shh/Gli3 mutants}

Consistent with the idea that Gli3 functions as a repressor of Shh signaling in the neural tube, the loss of ventral neuron generation in Shh null mice is rescued in Shh/ Gli3 compound mutants (Litingtung and Chiang 2000). It is not clear, however, whether dorsal-ventral patterning is restored in this situation. It is possible that the removal of Gli3 in the absence of the positional information normally provided by graded Shh signaling results in the generation of ventral neurons in a stochastic 
manner, irrespective of dorsal-ventral position. Subsequent neuronal migration could then account for the apparent reconstruction of dorsal-ventral pattern, independent of Shh, in a manner similar to that reported by Wichterle et al. (2002). To test this possibility, we examined whether the pattern of class I and class II progenitor homeodomain protein expression was restored in Shh/ Gli3 compound mutants. Restoration of dorsal-ventral pattern would provide evidence of a Shh-independent source of positional information in the neural tube.

In embryos lacking Shh, MNs and V2 neurons are missing, the expression of Pax7 is expanded ventrally, and V1 and V0 neurons are generated at the ventral midline (Fig. 4A,B; Litingtung and Chiang 2000). Consistent with this, expression of Nkx6.1 and Olig2 is absent (Fig. 4D,E, G,H), and Gsh1 is expanded ventrally (Fig. 4J, $\mathrm{K}$; data not shown). In embryos lacking both Gli3 and Shh there is a partial but dramatic rescue of ventral neural tube patterning (Fig. 4; Litingtung and Chiang 2000). Although the expression of Nkx2.2, HNF3 $\beta /$ FoxA2, and other Region A markers is not restored (Fig. 4I,F), Region $\mathrm{B}$ is rescued, with the class II proteins Nkx6.1 and Olig2 being expressed in ventral regions of the spinal cord (Fig. $4 \mathrm{~F}, \mathrm{I})$. Moreover, the position of Region $\mathrm{C}$ is rescued as the expression of $\mathrm{Db} \times 2$ and Nkx6.2 is restored to inter- mediate regions of the neural tube dorsal to Region $\mathrm{B}$ (Fig. 4C,F,O), and Pax7 and Gsh1 expression markers of Region $\mathrm{D}$ are restricted to the dorsal spinal cord (Fig. $4 C, L)$. These data are consistent with the idea that in the absence of Shh, Gli3 acts as a negative regulator of ventral spinal cord patterning. Thus these findings substantiate the idea that dorsal-ventral patterning of the neural tube progenitors is restored in Shh/Gli3 double mutants, arguing against the stochastic, pattern-independent generation of neurons in Shh/Gli3 mutants.

Although the evidence suggests that dorsal-ventral patterning of the spinal cord can proceed via a Shh-independent mechanism, the dorsal limits of expression of Dbx2 and Nkx6.2 were displaced dorsally in $S h^{-1-}$ Gli3 ${ }^{X t / X t J}$ compound mutants, and the ventral limit of Gsh1 expression was more dorsal than in wild-type embryos (Fig. 4C,F,L,O). Most markedly, the expansion of Nkx6.2 in $S h h^{-/-} /$Gli3 $^{X t / X t I}$ embryos resulted in many cells coexpressing Pax7 and Nkx6.2 (Fig. 4, cf. A and C), a situation similar to $X t^{J} / X t^{I}$ embryos (Fig. 2D) and contrasting with wild-type embryos, where few if any cells coexpress these two proteins (Figs. 2C, 4A). These data indicate that the defects in intermediate dorsal-ventral pattern characteristic of $X t^{I} / X t^{I}$ embryos-that is, the expansion of Region $C$ at the expense of Region D-are

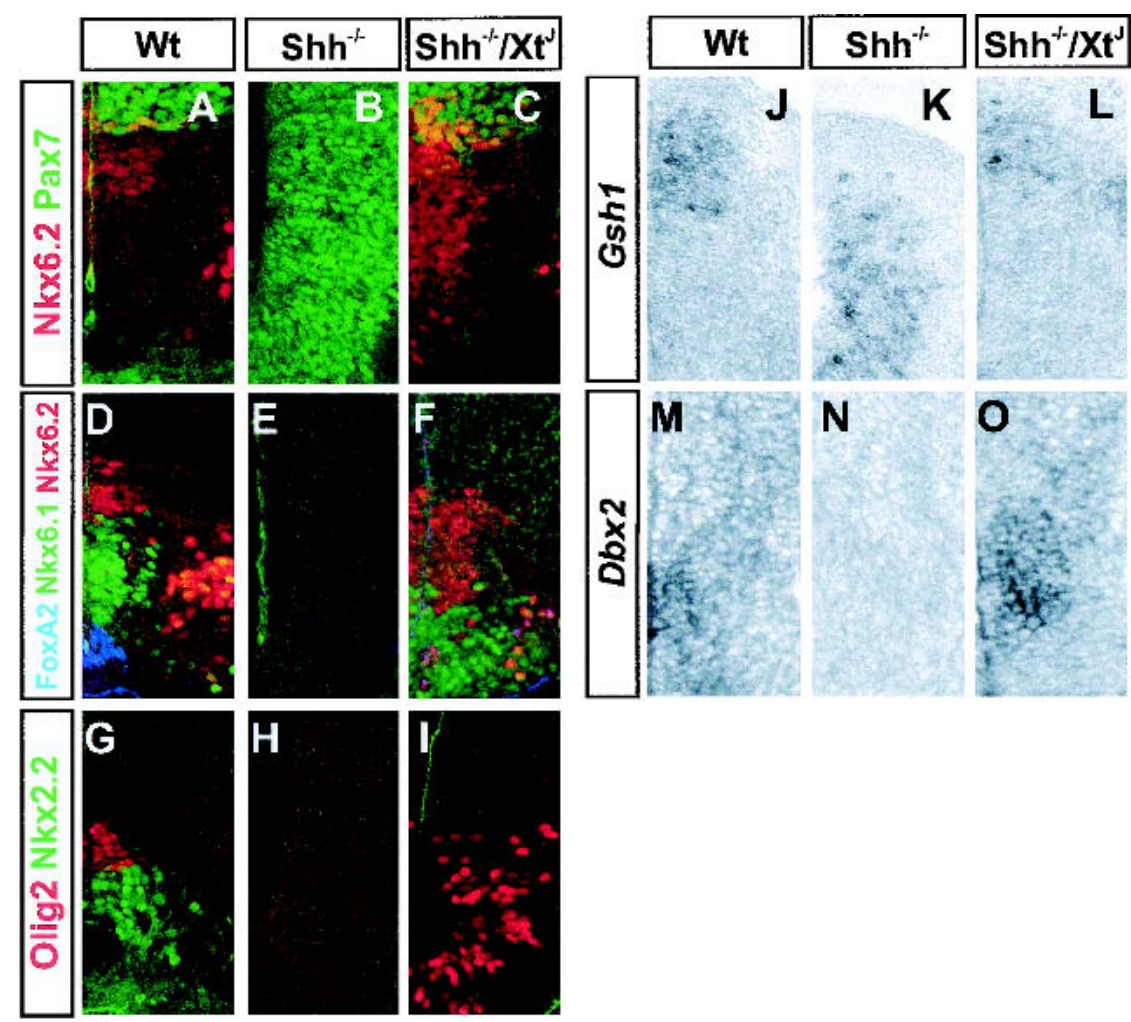

MNs in the ventral neural tube in these embryos (Litingtung and Chiang 2000). (J-L) Gsh1 expression is expanded ventrally in Shh ${ }^{-/-}$ mutants $(K)$, but in $S h h^{-/-} / G l i 3^{X t / X t I}$ compound mutants $(L)$ the dorsal restriction is restored. $(M-O)$ In Wt $(M)$ and Shh ${ }^{-/-} / \mathrm{Gli}^{X t / / X t J}$ compound mutants $(O), D b x 2$ expression is confined to the intermediate neural tube. $D b x 2$ is absent in $S h h^{-/-}$mutants $(N)$, which may be a consequence of the ventral expansion of Gsh1. All sections are from caudal regions of E11.5 embryos. Protein detection was by immunohistochemistry, and mRNA detection by in situ hybridization. 
also present in double-mutant mice lacking both Gli3 and Shh. This finding suggests that even in the absence of graded Shh signaling, Gli3 is required to correctly specify dorsal-ventral domains of gene expression in these regions of the spinal cord.

\section{Gli activity is required for patterning the entire ventral neural tube}

Although analysis of mice lacking Gli2 or Gli3 indicates that Gli proteins are required for some aspects of dorsalventral patterning, the generation of MNs and V2 neurons is largely unaffected in both Gli2 and Gli3 mutant embryos (Figs. 1, 2; Ding et al. 1998; Matise et al. 1998; Park et al. 2000). This raises the possibility that Glimediated transcription is not required for the generation of these cell types. Alternatively, it is possible that Gli2 and Gli3 are partially redundant and are able to substitute for each other in the generation of MNs and V2 neurons. To address this issue, we examined neuronal patterning under conditions in which transcription through all Gli proteins was blocked. To accomplish this, we use a construct, Gli3R, encoding a truncated Gli3 protein containing the $\mathrm{N}$-terminal and zinc finger domains equivalent to the proposed proteolytically processed Gli3 (Fig. 5A; Wang et al. 2000). In vitro, Gli3R blocks Shh/Gli-mediated transcription, acting as a dominant inhibitory Gli protein (data not shown). In contrast to Gli3 ${ }^{\Delta 699}$, which was expressed from the endogenous locus at wild-type levels, Gli3R was expressed ectopically, at high levels in more ventral regions of $\mathrm{HH}$ stage 10-12 chick neural tubes by in ovo electroporation (Fig. 5), and a coelectroporated GFP expression plasmid was used to identify cells transfected with Gli3R.

Electroporation of Gli3R results in the forced expression of Gli3R independent of Shh regulation, and this blocks all Hh responses in vivo. Ventrally located cells electroporated with Gli3R exhibited much lower levels of Ptc1 and Ptc2 expression than did cells at the same dorsal-ventral position on the control side (Fig. 5Bi-iii). The reduction in Ptc1 and Ptc2 did not reflect an inhibition of the specification of HNF3 $\beta /$ FoxA $2+$ floor plate (data not shown) or a decrease in the production of Shh (Fig. 5C). This result indicates that the reduced level of Ptc1 and Ptc2 expression caused by Gli3R results from the loss of response of neural cells to Shh signaling, and not from a decrease in the provision of Shh by the floor plate.

To test directly whether Gli activity is required for dorsal-ventral patterning throughout the ventral neural tube, we examined the expression of progenitor homeodomain proteins and the generation of neuronal subtypes in embryos transfected with Gli3R. Ectopic Gli3R had no obvious effect on homeodomain proteins expressed in dorsal Region D or the generation of dorsal neuronal subtypes (Fig. 5D,E; data not shown). However, ventrally, transfection of Gli3R resulted in the appearance of ectopic Pax7-, Pax6-, Gsh1-, Irx3-, and Dbx2expressing cells ventral to their normal domains of expression (Fig. 5D,E; data not shown); these cells coex- pressed GFP, indicating that the influence of Gli3R is cell-autonomous. Conversely, the expression of Nkx6.1, Olig2, and Nkx2.2, normally activated in response to Shh signaling, was inhibited in cells transfected with Gli3R (Fig. 5F-H). Consistent with this ventral-to-dorsal switch in progenitor cell identity, the generation of V0, $\mathrm{V} 1$, and V2 neurons and MNs was blocked by Gli3R within the normal domains of generation of these neurons (Fig. 5I,J; data not shown). In addition, the expression of Gli3R resulted in the cell-autonomous ectopic ventral generation of V1 neurons (data not shown). Thus, Gli3R expression in ventral neural progenitor cells resulted in cell-autonomous changes in the pattern of expression of all of the progenitor homeodomain proteins examined, corresponding to a ventral-to-dorsal shift in progenitor cell identity. Together, the data indicate that the specification of ventral progenitor cell pattern requires Gli activity throughout the ventral neural tube, and the repression of $\mathrm{MN}$ and $\mathrm{V} 2$ neuron generation suggests that the generation of these cell types in Gli2 and Gli3 mutant mice is not independent of Gli-mediated transcription.

\section{Discussion}

In this study we addressed the role of Gli proteins in spinal cord development. First, we identified a role for Gli3 repressor activity in the intermediate spinal cord, establishing a role for a processed Gli repressor isoform in vertebrates. Second, we demonstrated that dorsal-ventral patterning requires Gli protein-mediated transcription throughout the ventral neural tube. Taken together, these data indicate that there is a specific requirement for Gli3 in patterning the intermediate spinal cord, complementing the role of Gli2 in the most ventral regions, and they suggest that Gli proteins have redundant functions in the specification of ventral cell types including MNs and V2 neurons. Third, we show that dorsal-ventral patterning of the ventral neural tube is restored in Shh/Gli3 double mutants, consistent with the rescue of ventral neuronal subtype generation (Litingtung and Chiang 2000). These data argue against a stochastic mechanism generating neurons independent of dorsal-ventral position in Shh/Gli3 mutants, and they provide evidence of a patterning mechanism independent or parallel to graded Shh signaling. The details of this mechanism remain unclear. Our analysis, however, raises the possibility that Gli proteins act as common mediators of dorsal-ventral patterning, integrating Shh signals and other sources of positional information to control patterning of the ventral spinal cord.

\section{An essential role for Gli3 repressor activity in spinal cord development}

Our data establish a role for Gli3 in dorsal-ventral patterning of the spinal cord. In the absence of Gli3 there is a dorsal shift in the identity of intermediate progenitor domains at the expense of more dorsal progenitors (Fig. 

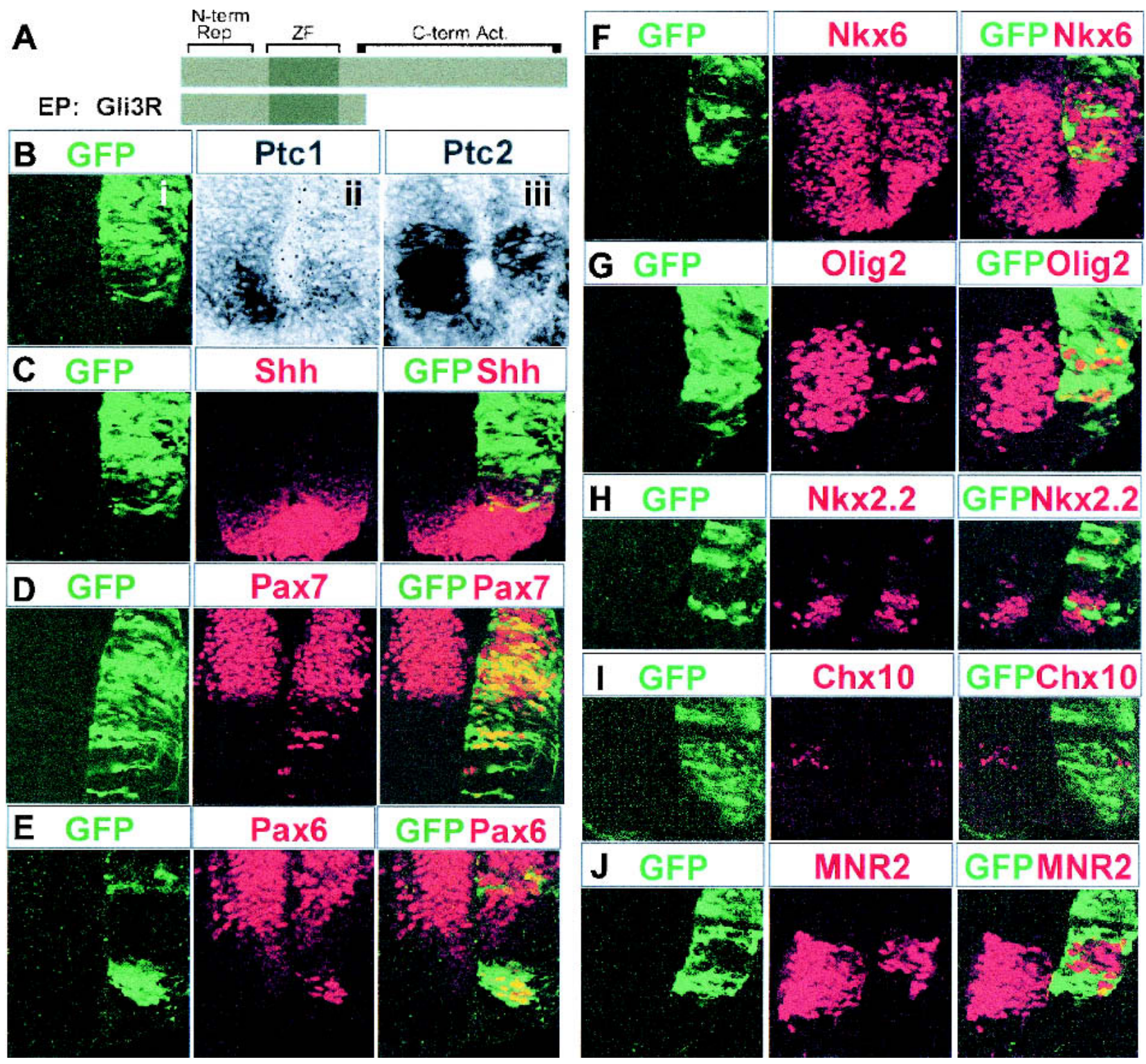

Figure 5. An inhibitory Gli protein blocks Shh responses throughout the ventral neural tube. HH stage 10-12 embryos were electroporated in ovo with Gli3R and GFP, and assayed 24-48 h later for the expression of the indicated genes. (A) Diagram summarizing the Gli3R construct. Zf, zinc finger DNA binding domain; N-term Rep, region of Gli3 N-terminal of the DNA binding domain implicated in repressing transcription; C-term Act, putative transcriptional activation domain C-terminal of the zinc finger domain. (Bi-iii) Adjacent sections of neural tube showing that expression of Ptc1 (ii) and Ptc2 (iii) is reduced in regions of neural tube electroporated with Gli3R as identified by GFP expression (i). (C) Expression of Shh (red) is unaffected in neural tubes transfected with Gli3R (green). $(D, E)$ Ectopic expression of Pax7 (D, red) and Pax6 (E, red) in the ventral neural tube of embryos expressing Gli3R (green). Not all cells that express Gli3R express Pax7; lateral GFP cells are likely to be neuronal and have downregulated Pax7, whereas the most ventral cells are likely to have been transfected after Pax7 had been inhibited or are expressing Gli3R below a threshold necessary to allow Pax7 expression (Briscoe et al. 2001). $(F-H)$ Ectopic expression of Gli3R, identified by GFP expression (green) inhibits Nkx6.1 $(F$, red). Olig2 $(G$, red) and Nkx2.2 ( $H$, red) expression in neural progenitor cells. Some coexpression of Gli3R and class II proteins can be seen, and this is likely to represent cells that express Gli3R below a threshold level necessary to inhibit the induction of the class II gene, or cells that have been transfected after the expression of the class II gene has been initiated (Briscoe et al. 2001). (I, $/)$ The generation of V2 neurons ( $I$, Chx10; red) and MNs (J, MNR2/HB9; red) is inhibited by the expression of Gli3R (green).

6). Together with studies describing a ventralization of the telencephalon in the forebrain of mice lacking Gli3 (Theil et al. 1999; Tole et al. 2000), our data suggest that Gli3 function is required for dorsal-ventral patterning along the entire rostral-caudal axis of the neural tube.
Not all progenitor homeodomain proteins expressed in these intermediate regions of the spinal cord are sensitive to loss of Gli3, and this results in combinations of progenitor homeodomain protein expression that are not encountered in normal conditions. Thus in $X t^{I} / X t^{J}$ em- 


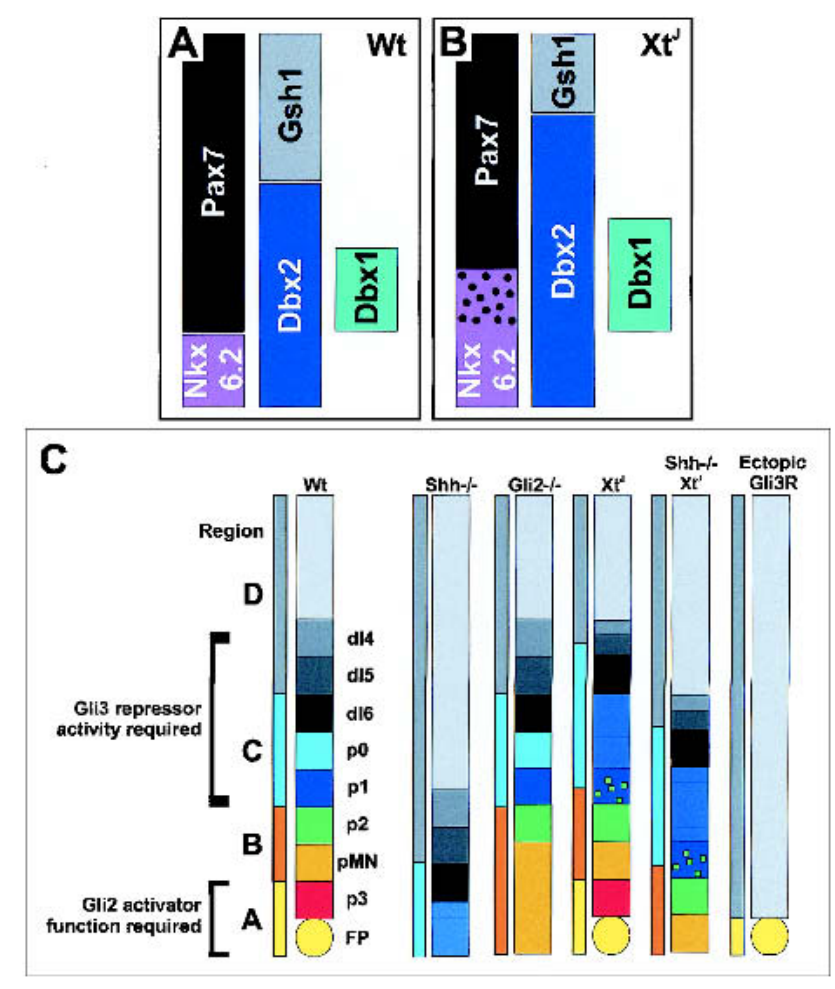

Figure 6. A model of Gli2 and Gli3 function in ventral neural tube patterning. $(A, B)$ Schematic diagrams comparing neural progenitor gene expression in intermediate regions of the spinal cord of wild-type $(A)$ and $X t^{I} / X t^{J}(B)$ embryos. $(C)$ Summary of the changes in neural progenitor identity within the ventral neural tube of embryos lacking Shh, expressing Gli3R, or lacking Gli2, Gli3, or both Gli3 and Shh. For details, see text.

bryos, the expression domains of Pax7 and Msx3 appear unchanged, resulting in progenitors expressing both Pax7 and Nkx6.2. The reason for the differences in sensitivity to loss of Gli3 may reflect different temporal requirements for Shh/Gli signaling, as Pax7 repression becomes independent of continued Shh signaling early during neural tube development (Ericson et al. 1996). Furthermore, in $X t^{I} / X t^{I}$ embryos, there is a frequent presence of cells coexpressing Nkx6.2 and Dbx1, a homeodomain protein combination not observed in wild-type neural progenitors. Cross-repressive interactions have been implicated in maintaining the mutual exclusive expression of Nkx6.2 and Dbx1 (Vallstedt et al. 2001), suggesting that Gli3 plays a critical role in establishing Nkx6.2-Dbx1 cross repression.

Concomitant with the changes in the expression patterns of the progenitor homeodomain proteins in $X t^{I} / X t^{J}$ embryos, the pattern of neuronal generation is disrupted. V1, V0, and dI6 neurons (Region C neurons) expand at the expense of dI5 and dI4 neurons (Region D; Fig. 2). However, the changes in neuronal pattern, while significant, are not as dramatic as might be expected given the changes in the expression of progenitor homeodomain proteins. For example, despite the dorsal expansion in the expression of Nkx6.2 and Dbx2, a progenitor code characteristic of V1 neurons, only a small proportion of
V1 neurons are found in ectopic dorsal locations (Fig. $2 \mathrm{I}, \mathrm{J})$. In light of the finding that $\operatorname{Pax} 7$ is implicated in repressing V1 neuron generation (Mansouri and Gruss 1998), the lack of an effect on Pax7 in $X t^{I} / X t^{I}$ embryos with its continued expression in Region $C$ may explain the limited expansion of V1 neurons observed. Moreover, the ectopic coexpression of Nkx6.2 and Dbx1 may affect the fate of neurons generated from these progenitors. Thus in $X t^{I} / X t^{I}$ embryos, the novel and mixed progenitor homeodomain codes that arise are likely to account for the changes in neuronal subtype generation observed.

Gli3 has been proposed to act as both a transcriptional repressor and activator (Dai et al. 1999; Sasaki et al. 1999). In Drosophila, proteolytic processing of Ci from an activator to a repressor isoform is well established (Aza Blanc et al. 1997; Robbins et al. 1997), and both repressor and activator isoforms of $\mathrm{Ci}$ are necessary and have distinct functions during Drosophila development (Methot and Basler 1999). There is emerging evidence that proteolytic processing is also a feature of Gli proteins (Dai et al. 1999; Aza Blanc et al. 2000; Wang et al. 2000). Our studies show that Gli3 ${ }^{\Delta 699}$, an isoform equivalent to a proteolytically processed version of Gli3, can substitute for Gli3 function, rescuing most if not all defects in gene expression and neuronal subtype identity observed in the spinal cord of $X t^{I} / X t^{I}$ mice. These data provide evidence of a role for repressor activity of Gli3 and suggest that proteolytic processing of Gli3 is functionally relevant in vertebrates.

Although spinal cord defects are rescued in Gli3 ${ }^{\Delta 699 / \Delta 699}$ embryos, other aspects of development are severely affected (Böse et al. 2002). The defects seen in Gli3 ${ }^{\Delta 699 / \Delta 699}$ mice resemble those of Pallister Hall syndrome and include limb polydactyly, gut malformation, and defects in kidney development. Moreover, recent evidence from Litingtung et al. (2002) and te Welscher et al. (2002) suggests that the balance of Gli3 transcriptional activator and repressor activities specifies digit identity in limb buds. The requirement for full-length activator and $\mathrm{N}$ terminal repressor forms, therefore, differs between tissues and could be considered analogous to the differential requirement for repressor and activator forms of $\mathrm{Ci}$ during Drosophila development (Methot and Basler 1999).

\section{An essential role for Gli activity in dorsal-ventral patterning of the spinal cord}

Embryos lacking individual Gli proteins have limited dorsal-ventral patterning defects. Region A, encompassing the floor plate and V3 neurons, is markedly reduced in embryos lacking Gli2 (Ding et al. 1998; Matise et al. 1998), and the patterning of the intermediate spinal cord is disrupted in $X t^{t} / X t^{I}$ embryos. However, Region B, which generates MNs and V2 neurons, is still present in both mutants (Fig. 6). It is possible that MNs and V2 neurons are generated by a Gli-independent mechanism; however, the forced expression of a dominant Gli repressor protein, Gli3R, indicates that the generation of these 
cell types can be blocked by inhibiting Gli-mediated transcription. These data suggest a central role for Glimediated transcriptional control in the generation of ventral neurons and argue for functional redundancy between Gli proteins. Consistent with this idea, it was proposed that Gli2 and Gli3 have redundant functions during lung, skeletal, and tooth development (Mo et al. 1997; Hardcastle et al. 1998; Motoyama et al. 1998). Moreover, Gli2 and Gli3 can function as both repressors and activators of transcription, and Gli binding sites confer responsiveness to each of the Gli proteins, in vitro (Dai et al. 1999; Sasaki et al. 1999). The loss of Regions B and C in embryos lacking Smo (Wijgerde et al. 2002) indicates that Shh signaling is required for the specification of these regions, and together the data suggest that either Gli2 or Gli3 activator function is sufficient, individually, in this region of the neural tube.

The identification of specific patterning defects in embryos lacking either Gli2 or Gli3 shows that neither gene completely substitutes for the other during spinal cord development. The loss of the most ventral region of the spinal cord in the absence of Gli2 indicates that Gli3 is unable to substitute for Gli2 induction of the highest Shh responses, and agrees with data indicating that Gli2 primarily functions as an activator (Bai and Joyner 2001). Conversely, the dorsal expansion of Region $\mathrm{C}$ in $X t^{J} / X t^{J}$ embryos suggests that Gli2 is unable to fully replace the repressor function of Gli3. These findings may reflect qualitative differences in the intrinsic activity of Gli2 and Gli3 or the differential spatial and temporal expression of the two genes during neural tube development (Sasaki et al. 1997; Ruiz i Altaba 1998). It appears likely, however, that a combination of these factors accounts for the nonredundant activities of Gli2 and Gli3.

\section{Shh independent patterning of the neural tube requires Gli proteins}

Our present analysis confirms the rescue of ventral neuronal generation in embryos lacking Shh and Gli3 (Litingtung and Chiang 2000). Moreover, our data indicate that the expression patterns of progenitor homeodomain proteins are rescued in $S h h / X t^{I}$ compound mutant embryos (Fig. 6). These findings are consistent with the rescue of ventral cell types in Shh/Smo double mutants (Wijgerde et al. 2002) and argue against a stochastic, pattern-independent generation of neurons in double-mutant embryos. The findings are in favor of a mechanism that can direct patterning of the ventral neural tube, at least in part, independently of graded Shh signaling.

Strikingly, we observed similar patterning defects in the intermediate spinal cord of $\mathrm{Shh}^{-/-} / \mathrm{Gli}^{\mathrm{XtJ} / \mathrm{XtJ}}$ double mutants as in $X t^{I} / X t^{I}$ embryos: Region $\mathrm{C}$ is expanded dorsally at the expense of Region D, and there is a marked increase in the number of cells that coexpress Nkx6.2 and Pax7 (Figs. 3H, 4C, 6). Thus, whatever the Shh-independent patterning mechanism is, Gli3 is required for the correct positioning of progenitor domains in the intermediate neural tube. Together with evidence that Gli-mediated transcription is required for the gen- eration of most if not all ventral neuronal subtypes (Fig. $5)$, the data raise the possibility that Gli proteins are required for the correct patterning of the neural tube even in the absence of graded Shh signaling.

The nature of the signal(s) conferring positional information independent of Shh remains unclear. It is possible that other Hh genes, such as Ihh, which is expressed in gastrulating embryos in regions of the embryo close to the forming neural plate, are able to partially substitute for Shh (Dyer et al. 2001). Alternatively, it is possible that Wnt signals (Muroyama et al. 2002) or BMP signals emanating from the dorsal neural tube and BMP antagonists expressed ventrally are sufficient to provide positional information (Lee and Jessell 1999). BMPs and Shh have opponent activity in the specification of ventral neuronal identity, and a reduction in BMP signaling leads to the expansion of ventral neural fates (Barth et al. 1999; Liem et al. 2000; Nguyen et al. 2000; Patten and Placzek 2002; Timmer et al. 2002). Thus BMP signaling may be sufficient to provide positional information throughout the neural tube in embryos lacking Gli3 and Shh.

Together the data indicate that the signaling mechanisms that direct dorsal and ventral neural tube patterning are linked and that the limits of influence of ventral and dorsal signals are not clearly defined. Thus it seems likely that individual progenitor cells determine their gene expression profile by integrating the various dorsal and ventral extracellular signals that influence progenitor cell patterning. The data suggest that Gli proteins are part of this activity and may act as common mediators to integrate extracellular patterning signals. Consistent with this idea, as well as responding to Shh signaling, Gli proteins have been proposed to mediate Wnt signals (Mullor et al. 2001); in addition, GSK3, a component of the Wnt signaling pathway, is implicated in influencing Ci activity in Drosophila (Jia et al. 2002; Price and Kalderon 2002). Moreover, BMPs are proposed to inhibit Shh signaling at a proximal point on the Shh signaling pathway (Liem et al. 2000), and there is evidence that Smads-the transcriptional effectors of BMP signalingphysically associate with Gli proteins (Liu et al. 1998). The level of Gli activity may therefore function as an intracellular correlate of positional information provided by extracellular patterning signals. In this model, Gli proteins act as pivotal intermediaries, interpreting patterning signals by directing the expression of class I and class II proteins that control neuronal subtype identity.

\section{Materials and methods}

\section{Mutant mice lines}

Embryos lacking functional Gli3 were generated from mice containing the $X t^{I}$ allele, which has a deletion encompassing the zinc finger region of Gli3 (Hui and Joyner 1993; Büscher et al. 1998; Ruiz i Altaba 1998; Maynard et al. 2002), as the first zinc finger is not involved in the specific binding to DNA (Pavletich and Pabo 1993), $X t^{J}$ is likely to be a null allele (Büscher et al. 1998). The Gli3 ${ }^{\Delta 699}$ allele has been described (Böse et al. 2002) 
and has a PGKneoNTRtkpA cassette inserted into the first exon $3^{\prime}$ of the zinc finger region of Gli3. This allele generates an abnormal splicing event that causes a loss of Gli3 coding sequences, an apparent frameshift, and a predicted protein termination codon (Böse et al. 2002). The mutant allele terminates just C-terminal of the zinc finger domain (amino acid. position 699), in close proximity to the mutations identified in Pallister Hall syndrome patients with 21 additional residues of abnormal protein sequence between the splice site and the stop codon. As a consequence these mice generate a truncated Gli3 protein consisting of 720 amino acids compared to the predicted length of 1588 amino acids of the wild-type Gli3.

\section{Chick in ovo electroporation}

Human Gli3 encoding amino acids 1-768, termed Gli3R, was inserted in the electroporation vector pCAGGS and coelectroporated with an EGFP expression vector into the neural tube of stage $\mathrm{HH}$ (Hamburger and Hamilton 1953) 10-12 chick embryos (Briscoe et al. 2000). After 24-48 h, embryos were fixed and processed for immunohistochemistry.

Immunohistochemistry and in situ hybridization histochemistry

Immunohistochemical localization of proteins was performed as described (Yamada et al. 1993; Briscoe et al. 2000). Antibodies used are as described (Ericson et al. 1996, 1997; Tanabe et al. 1998; Pierani et al. 1999; Vallstedt et al. 2001; Müller et al. 2002). Images were collected on a Zeiss LSM510 or Leica TCS SP2 confocal microscope. In situ hybridization was performed as described (Schaeren-Wiemers and Gerfin-Moser 1993), using probes for Dbx2 (Pierani et al. 1999), Gsh1 (HGMP Resource Centre), Ptc1 and Ptc2 (Pearse et al. 2001), and Gli3 (PCR product from E11.5 mouse cDNA library).

\section{Acknowledgments}

We thank S. Morton for antibodies, K. Campbell for Gsh cDNAs, H. Edlund for pan Nkx6 antisera, T. Müller for Lbx1 antisera, A. Peirani for anti-Dbx1, R. Zeller for $\mathrm{Xt}^{\mathrm{J}}$ and Shh null mice, and A. Mynett for technical assistance. We thank T. Jessell, D. Stemple, J-P. Vincent, and D. Wilkinson for helpful discussion and comments on the manuscript, and M. Wijgerde and A. McMahon for communicating data prior to publication. D.S. and J.B. are supported by the MRC; J.E. is supported by the Royal Swedish Academy of Sciences by a donation from the Wallenberg Foundation, The Swedish Foundation for Strategic Research, The Swedish National Research Council, Project A.L.S., and the Karolinska Institute. U.R. is supported by the Deutsche Forschungregemeinscheft. This work was funded in part by the EC network grant, Brainstem Genetics, QLRT-2000-01467.

The publication costs of this article were defrayed in part by payment of page charges. This article must therefore be hereby marked "advertisement" in accordance with 18 USC section 1734 solely to indicate this fact.

\section{References}

Aza-Blanc, P., Ramirez-Weber, F.A., Laget, M.P., Schwartz, C., and Kornberg, T.B. 1997. Proteolysis that is inhibited by hedgehog targets Cubitus interruptus protein to the nucleus and converts it to a repressor. Cell 89: 1043-1053.

Aza-Blanc, P., Lin, H.Y., Ruiz i Altaba, A., and Kornberg, T.B. 2000. Expression of the vertebrate Gli proteins in Drosophila reveals a distribution of activator and repressor activities. Development 127: 4293-4301.

Bai, C.B. and Joyner, A.L. 2001. Gli1 can rescue the in vivo function of Gli2. Development 128: 5161-5172.

Barth, K.A., Kishimoto, Y., Rohr, K.B., Seydler, C., SchulteMerker, S., and Wilson, S.W. 1999. Bmp activity establishes a gradient of positional information throughout the entire neural plate. Development 126: 4977-4987.

Böse, J., Grotewold, L., and Rüther, U. 2002. Pallister-Hall syndrome phenotype in mice mutant for Gli3. Hum. Mol. Genet. 11: 1129-1135.

Briscoe, J. and Ericson, J. 2001. Specification of neuronal fates in the ventral neural tube. Curr. Opin. Neurobiol. 11: 43-49.

Briscoe, J., Sussel, L., Serup, P., Hartigan-O'Connor, D., Jessell, T.M., Rubenstein, J.L., and Ericson, J. 1999. Homeobox gene Nkx2.2 and specification of neuronal identity by graded Sonic hedgehog signaling. Nature 398: 622-622.

Briscoe, J., Pierani, A., Jessell, T.M., and Ericson, J. 2000. A homeodomain code specifies progenitor cell identity and neuronal fate in the ventral neural tube. Cell 101: 435-445.

Briscoe, J., Chen, Y., Jessell, T.M., and Struhl, G. 2001. A hedgehog-insensitive form of patched provides evidence for direct long-range patterning activity of Sonic hedgehog in the neural tube. Mol. Cell 7: 1279-1291.

Büscher, D., Grotewold, L., and Rüther, U. 1998. The XtJ allele generates a Gli3 fusion transcript. Mamm. Genome 9: 676678.

Chiang, C., Litingtung, Y., Lee, E., Young, K.E., Corden, J.L., Westphal, H., and Beachy, P.A. 1996. Cyclopia and defective axial patterning in mice lacking Sonic hedgehog gene function. Nature 383: 407-413.

Dai, P., Akimaru, H., Tanaka, Y., Maekawa, T., Nakafuku, M., and Ishii, S. 1999. Sonic Hedgehog-induced activation of the Gli1 promoter is mediated by GLI3. I. Biol. Chem. 274: $8143-8152$.

Ding, Q., Motoyama, J., Gasca, S., Mo, R., Sasaki, H., Rossant, J., and Hui, C.C. 1998 Diminished Sonic hedgehog signaling and lack of floor plate differentiation in Gli2 mutant mice. Development 125: 2533-2543.

Dyer, M.A., Farrington, S.M., Mohn, D., Munday, J.R., and Baron, M.H. 2001. Indian hedgehog activates hematopoiesis and vasculogenesis and can respecify prospective neurectodermal cell fate in the mouse embryo. Development 128: $1717-1730$.

Eggenschwiler, J.T., Espinoza, E., and Anderson, K.V. 2001. Rab23 is an essential negative regulator of the mouse Sonic hedgehog signaling pathway. Nature 412: 194-198.

Ericson, J., Thor, S., Edlund, T., Jessell, T.M., and Yamada, T. 1992. Early stages of motor neuron differentiation revealed by expression of homeobox gene Islet-1. Science 256: 15551560.

Ericson, J., Morton, S., Kawakami, A., Roelink, H., and Jessell, T.M. 1996. Two critical periods of Sonic Hedgehog signaling required for the specification of motor neuron identity. Cell 87: 661-673.

Ericson, J., Rashbass, P., Schedl, A., Brenner-Morton, S., Kawakami, A., van Heyningen, V., Jessell, T. M., and Briscoe, J. 1997. Pax6 controls progenitor cell identity and neuronal fate in response to graded Shh signaling. Cell 90: $169-180$

Goodrich, L.V., Milenkovic, L., Higgins, K.M., and Scott, M.P. 1997. Altered neural cell fates and medulloblastoma in mouse patched mutants. Science 277: 1109-1113.

Gritli-Linde, A., Lewis, P., McMahon, A.P., and Linde, A. 2001 The whereabouts of a morphogen: Direct evidence for shortand graded long-range activity of hedgehog signaling pep- 
tides. Dev. Biol. 236: 364-386.

Gross, M.K., Dottori, M., and Goulding, M. 2002. Lbx1 specifies somatosensory association interneurons in the dorsal spinal cord. Neuron 34: 535-549.

Hamburger, H. and Hamilton, H.L. 1953. A series of normal stages in the development of the chick embryo. J. Morphol. 88: 49-92.

Hardcastle, Z., Mo, R., Hui, C.C. and Sharpe, P.T. 1998. The Shh signaling pathway in tooth development: Defects in Gli2 and Gli3 mutants. Development 125: 2803-2811.

Hui, C.C. and Joyner, A.L. 1993. A mouse model of greig cephalopolysyndactyly syndrome: The extra-toesJ mutation contains an intragenic deletion of the Gli3 gene. Nat. Genet. 3: 241-246.

Hui, C.C., Slusarski, D., Platt, K.A., Holmgren, R., and Joyner, A.L. 1994. Expression of three mouse homologs of the Drosophila segment polarity gene cubitus interruptus, Gli, Gli-2 and Gli-3 in ectoderm- and mesoderm-derived tissues suggests multiple roles during postimplantation development. Dev. Biol. 162: 402-413.

Hynes, M., Ye, W., Wang, K., Stone, D., Murone, M., Sauvage, F., and Rosenthal, A. 2000. The seven-transmembrane receptor smoothened cell-autonomously induces multiple ventral cell types. Nat. Neurosci. 3: 41-46.

Ingham, P.W. 1998. Transducing Hedgehog: The story so far. EMBO J. 17: 3505-3511.

Ingham, P.W. and McMahon, A.P. 2001. Hedgehog signaling in animal development: Paradigms and principles. Genes \& Dev. 15: 3059-3087.

Jessell, T.M. 2000. Neuronal specification in the spinal cord: Inductive signals and transcriptional codes. Nat. Rev. Genet. 1: 20-29.

Jia, J., Amanai, K., Wang, G., Tang, J., Wang, B., and Jiang, J. 2002. Shaggy/GSK3 antagonizes Hedgehog signaling by regulating Cubitus interruptus. Nature 416: 548-552.

Krishnan, V., Pereira, F.A., Qiu, Y., Chen, C.H., Beachy, P.A., Tsai, S.Y., and Tsai, M.J. 1997. Mediation of Sonic hedgehoginduced expression of COUP-TFII by a protein phosphatase. Science 278: 1947-1950.

Lee, J., Platt, K.A., Censullo, P., and Ruiz i Altaba, A. 1997. Gli1 is a target of Sonic hedgehog that induces ventral neural tube development. Development 124: 2537-2552.

Lee, K.J. and Jessell, T.M. 1999. The specification of dorsal cell fates in the vertebrate central nervous system. Annu. Rev. Neurosci. 22: 261-294.

Lewis, P.M., Dunn, M.P., McMahon, J.A., Logan, M., Martin, J.F., St-Jacques, B., and McMahon, A.P. 2001 Cholesterol modification of sonic hedgehog is required for long-range signaling activity and effective modulation of signaling by Ptc1. Cell 105: 599-612.

Liem, K.F., Jessell, T.M., and Briscoe, J. 2000. Regulation of the neural patterning activity of sonic hedgehog by secreted BMP inhibitors expressed by notochord and somites. Development 127: 4855-4866.

Litingtung, Y. and Chiang, C. 2000. Specification of ventral neuron types is mediated by an antagonistic interaction between Shh and Gli3. Nat. Neurosci. 3: 979-985.

Litingtung, Y., Dahn, R.D., Li, Y., Fallon, J.F., and Chiang, C. 2002 Shh and Gli3 are dispensable for limb skeleton formation but regulate digit number and identity. Nature 418: 979-983

Liu, F., Massague, J., and Ruiz i Altaba, A. 1998. Carboxy-terminally truncated Gli3 proteins associate with Smads. Nat. Genet. 20: 325-326.

Mansouri, A. and Gruss, P. 1998. Pax3 and Pax7 are expressed in commissural neurons and restrict ventral neuronal identity in the spinal cord. Mech. Dev. 78: 171-178.

Marigo, V., Johnson, R.L., Vortkamp, A., and Tabin, C.J. 1996. Sonic hedgehog differentially regulates expression of GLI and GLI3 during limb development. Dev. Biol. 180: 273-283.

Matise, M.P., Epstein, D.J., Park, H.L., Platt, K.A., and Joyner, A.L. 1998. Gli2 is required for induction of floor plate and adjacent cells, but not most ventral neurons in the mouse central nervous system. Development 125: 2759-2770.

Maynard, T.M., Jain, M.D., Balmer, C.W., and LaMantia, A.S. 2002. High-resolution mapping of the Gli3 mutation extratoes reveals a $51.5-\mathrm{kb}$ deletion. Mamm. Genome. 13: 58-61.

Methot, N. and Basler, K. 1999. Hedgehog controls limb development by regulating the activities of distinct transcriptional activator and repressor forms of Cubitus interruptus. Cell 96: 819-831.

. 2001. An absolute requirement for Cubitus interruptus in Hedgehog signaling. Development 128: 733-742.

Mo, R., Freer, A.M., Zinyk, D.L., Crackower, M.A., Michaud, J., Heng, H.H., Chik, K.W., Shi, X.M., Tsui, L.C., Cheng, S.H., et al. 1997. Specific and redundant functions of Gli2 and Gli3 zinc finger genes in skeletal patterning and development. Development 124: 113-123.

Motoyama, J., Liu, J., Mo, R., Ding, Q., Post, M., and Hui, C.C. 1998 Essential function of Gli2 and Gli3 in the formation of lung, trachea and oesophagus. Nat Genet. 20: 54-57.

Muhr, J., Andersson, E., Persson, M., Jessell, T.M., and Ericson, J. 2001. Groucho-mediated transcriptional repression establishes progenitor cell pattern and neuronal fate in the ventral neural tube. Cell 104: 861-873.

Müller, T., Brohmann, H., Pierani, A., Heppenstall, P.A., Lewin, G.R., Jessell, T.M., and Birchmeier, C. 2002. The homeodomain factor Lbxl distinguishes two major programs of neuronal differentiation in the dorsal spinal cord. Neuron 34: 551-562.

Mullor, J.L., Dahmane, N., Sun, T., and Ruiz i Altaba, A. 2001. Wnt signals are targets and mediators of Gli function. Curr. Biol. 11: 769-773.

Muroyama, Y., Fujihara, M., Ikeya, M., Kondoh, H., and Takada, S. 2002. Wnt signaling plays an essential role in neuronal specification of the dorsal spinal cord. Genes \& Dev. 16: $548-553$.

Nguyen, V.H., Trout, J., Connors, S.A., Andermann, P., Weinberg, E., and Mullins, M.C. 2000. Dorsal and intermediate neuronal cell types of the spinal cord are established by a BMP signaling pathway. Development 127: 1209-1220.

Novitch, B., Chen, A.I., and Jessell, T.M. 2001. Coordinate regulation of motor neuron subtype identity and pan-neural properties by the bHLH repressor Olig2. Neuron 31: 773-789.

Ohlmeyer, J.T. and Kalderon, D. 1998. Hedgehog stimulates maturation of Cubitus interruptus into a labile transcriptional activator. Nature 396: 749-753.

Pabst, O., Herbrand, H., Takuma, N., and Arnold, H.H. 2000. NKX2 gene expression in neuroectoderm but not in mesendodermally derived structures depends on sonic hedgehog in mouse embryos. Dev. Genes Evol. 210: 47-50.

Park, H.L., Bai, C., Platt, K.A., Matise, M.P., Beeghly, A., Hui, C.C., Nakashima, M., and Joyner, A.L. 2000. Mouse Gli1 mutants are viable but have defects in SHH signaling in combination with a Gli2 mutation. Development 127: 1593-1605.

Patten, I. and Placzek, M. 2002. Opponent activities of Shh and BMP signaling during floor plate induction in vivo. Curr. Biol. 12: 47-52.

Pavletich, N.P. and Pabo, C.O. 1993. Crystal structure of a fivefinger GLI-DNA complex: New perspectives on zinc fingers. Science 261: 1701-1707. 
Pearse II, R.V., Vogan, K.J., and Tabin, C.J. 2001. Ptc1 and Ptc2 transcripts provide distinct readouts of Hedgehog signaling activity during chick embryogenesis. Dev. Biol. 239: 15-29.

Pierani, A., Brenner-Morton, S., Chiang, C., and Jessell, T.M. 1999. A sonic hedgehog-independent, retinoid-activated pathway of neurogenesis in the ventral spinal cord. Cell 97: 903-915.

Pierani, A., Moran-Rivard, L., Sunshine, M.J., Littman, D.R., Goulding, M., and Jessell, T.M. 2001. Control of interneuron fate in the developing spinal cord by the progenitor homeodomain protein Dbx1. Neuron 29: 367-384.

Price, M.A. and Kalderon, D. 2002. Proteolysis of the Hedgehog signaling effector Cubitus interruptus requires phosphorylation by Glycogen Synthase Kinase 3 and Casein Kinase 1. Cell 108: 823-835.

Qiu, M., Shimamura, K., Sussel, L., Chen, S., and Rubenstein, J.L. 1998. Control of anteroposterior and dorsoventral domains of Nkx-6.1 gene expression relative to other $\mathrm{Nkx}$ genes during vertebrate CNS development. Mech. Dev. 72: 77-88.

Robbins, D.J., Nybakken, K.E., Kobayashi, R., Sisson, J.C., Bishop, J.M., and Therond, P.P. 1997. Hedgehog elicits signal transduction by means of a large complex containing the kinesin-related protein costal2. Cell 90: 225-234.

Ruiz i Altaba, A. 1998. Combinatorial Gli gene function in floor plate and neuronal inductions by Sonic hedgehog. Development 125: 2203-2212.

Ruppert, J.M., Kinzler, K.W., Wong, A.J., Bigner, S.H., Kao, F.T., Law, M.L., Seuanez, H.N., O'Brien, S.J., and Vogelstein, B. 1988. The GLI-Kruppel family of human genes. Mol. Cell Biol. 8: 3104-3113.

Sasaki, H., Hui, C., Nakafuku, M., and Kondoh, H. 1997. A binding site for Gli proteins is essential for HNF-3beta floor plate enhancer activity in transgenics and can respond to Shh in vitro. Development 124: 1313-1322.

Sasaki, H., Nishizaki, Y., Hui, C., Nakafuku, M., and Kondoh, H. 1999. Regulation of Gli2 and Gli3 activities by an aminoterminal repression domain: Implication of Gli2 and Gli3 as primary mediators of Shh signaling. Development 126: 3915-3924.

Schaeren-Wiemers, N. and Gerfin-Moser, A. 1993. A single protocol to detect transcripts of various types and expression levels in neural tissue and cultured cells: In situ hybridization using digoxigenin-labeled cRNA probes. Histochemistry 100: 431-440.

Tanabe, Y., William, C., and Jessell, T.M. 1998. Specification of motor neuron identity by the MNR2 homeodomain protein. Cell 95: 67-80.

te Welscher, P., Zuniga, A., Kuijper, S., Drenth, T., Goedemans, H., Meijlink, F., and Zeller, R. 2002. Progression of vertebrate limb development through $\mathrm{SHH}$-mediated counteraction of GLI3. Science (In press).

Theil, T., Alvarez-Bolado, G., Walter, A., and Rüther, U. 1999. Gli3 is required for Emx gene expression during dorsal telencephalon development. Development 126: 3561-3571.

Timmer, J.R., Wang, C., and Niswander, L. 2002. BMP signaling patterns the dorsal and intermediate neural tube via regulation of homeobox and helix-loop-helix transcription factors. Development. 129: 2459-2472.

Tole, S., Ragsdale, C.W., and Grove, E.A. 2000. Dorsoventral patterning of the telencephalon is disrupted in the mouse mutant extra-toes(J). Dev. Biol. 217: 254-265.

Vallstedt, A., Muhr, J., Pattyn, A., Pierani, A., Mendelsohn, M., Sander, M., Jessell, T.M., and Ericson, J. 2001. Different levels of repressor activity assign redundant and specific roles to Nkx6 genes in motor neuron and interneuron specification.
Neuron 31: 743-755.

von Mering, C. and Basler, K. 1999. Distinct and regulated activities of human Gli proteins in Drosophila. Curr. Biol. 9: 1319-1322.

Wang, B., Fallon, J.F., and Beachy, P.A. 2000. Hedgehog-regulated processing of Gli3 produces an anterior/posterior repressor gradient in the developing vertebrate limb. Cell 100: 423-434.

Wichterle, H., Lieberam, I., Porter, J., and Jessell, T.M. 2002. Directed differentiation of embryonic stem cells into spinal motor neurons. Cell 110: 385-397

Wijgerde, M., McMahan, J.A., Rule, M., and McMahon, A.P. 2002. A direct requirement for Hedgehog signaling for normal specification of all ventral progenitor domains presumptive mammalian spinal cord. Genes \& Dev. (this issue).

Yamada, T., Pfaff, S.L., Edlund, T., and Jessell, T.M. 1993. Control of cell pattern in the neural tube: Motor neuron induction by diffusible factors from notochord and floor plate. Cell 73: 673-686. 


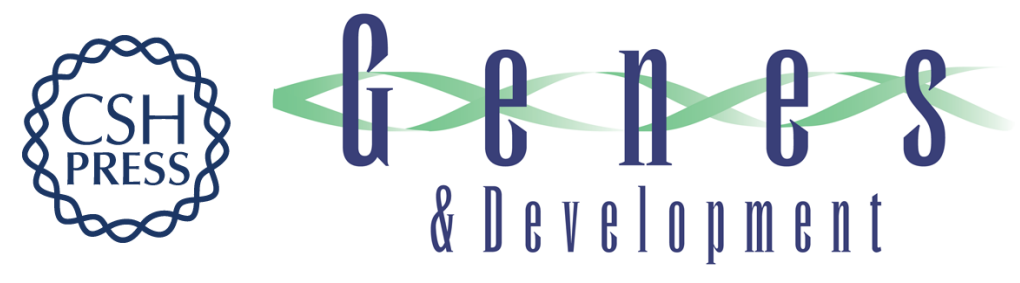

\section{Dorsal-ventral patterning of the spinal cord requires Gli3 transcriptional repressor activity}

Madelen Persson, Despina Stamataki, Pascal te Welscher, et al.

Genes Dev. 2002, 16:

Access the most recent version at doi:10.1101/gad.243402

References This article cites 77 articles, 27 of which can be accessed free at: http://genesdev.cshlp.org/content/16/22/2865.full.html\#ref-list-1

License

Email Alerting

Receive free email alerts when new articles cite this article - sign up in the box at the top Service right corner of the article or click here.

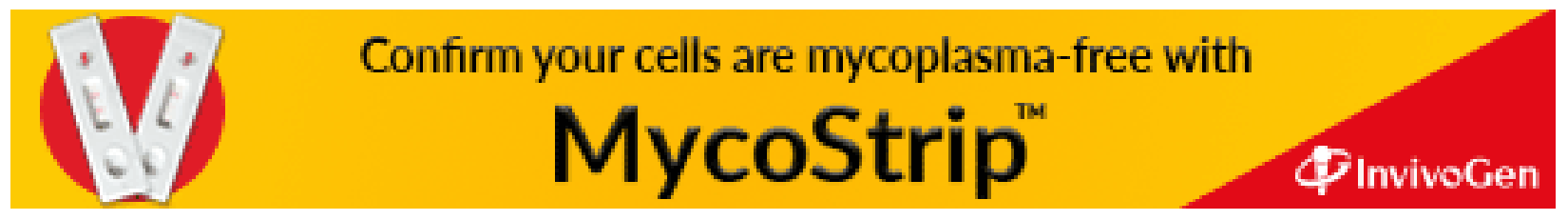

